
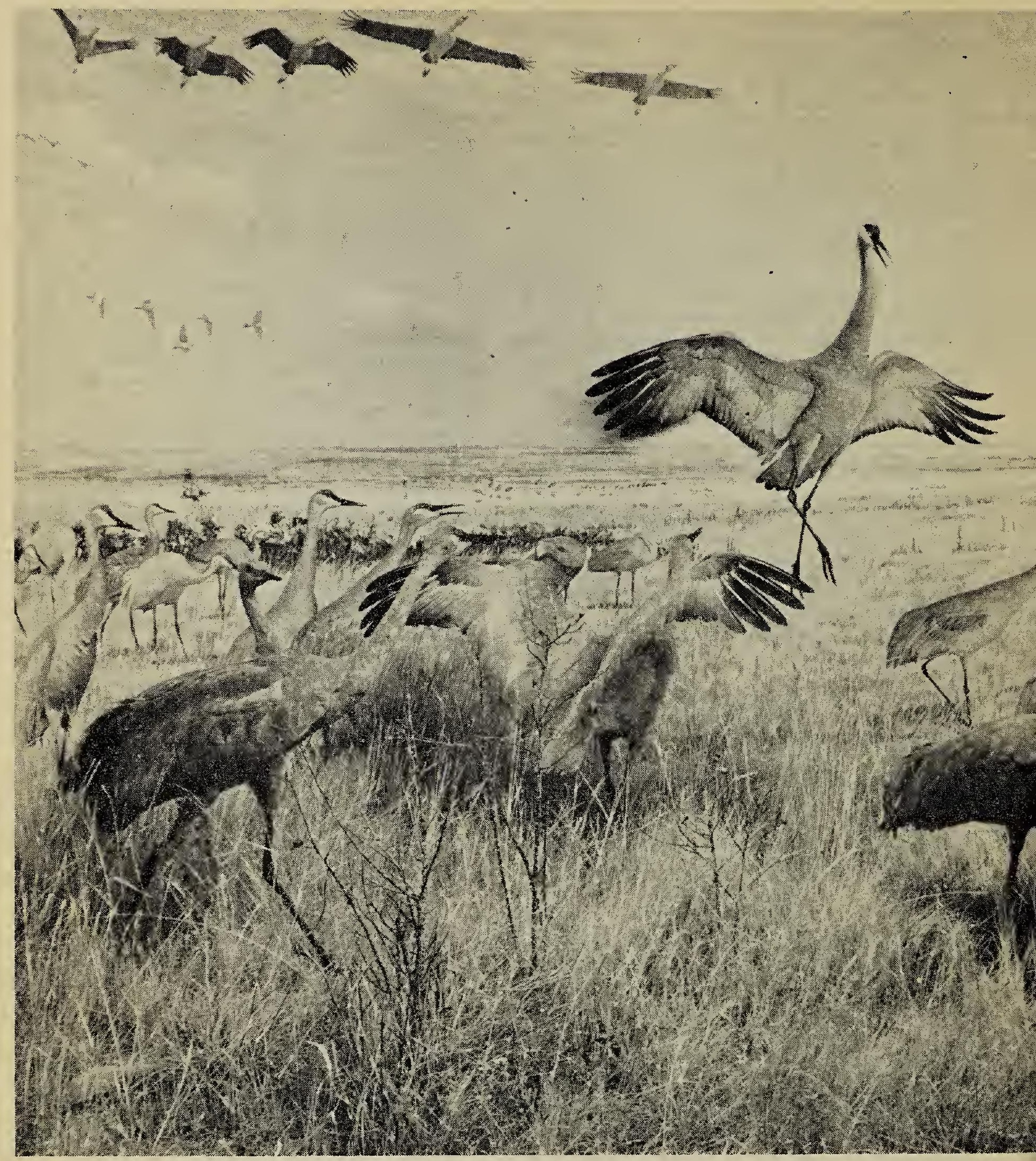

\title{
Museum Sandhill Cranes Habitat Group
}

by Dave Green, Regina

More wild and intractable than their environment, the Sandhill Cranes of North America lend to the spring and autumn skies above Saskatchewan a flavor of timelessness. To see Sandhill Cranes passing overhead in spring and fall migration and to hear their purling cry is to be a party to an unforgettable encounter, and at their resting place on Last Mountain Lake the birds present a spectacle that people have travelled thousands of miles to see.

Fortunately for the cranes, the flocking of the Sandhills at "The Fingers" on the northern end of the lake was not lost upon the early settlers in the area, who recognized it as an outstanding natural phenomenon. The area was set aside as a sanctuary in 1887. 
